\title{
Cathodic Stripping Voltammetric Determination of Febuxostat in Pharmaceutical Dosage Form and Plasma Samples
}

\author{
I. H. I. Habib, ${ }^{a,}$ M. S. Rizk, ${ }^{b}$ M. M. Abou El-Alamin ${ }^{b}$ and G. S. Imam ${ }^{c}$ \\ ${ }^{a}$ Applied Organic Chemistry Department, National Research Center, Dokki, Cairo, Egypt \\ ${ }^{b}$ Analytical Chemistry Department, Faculty of Pharmacy, Helwan University, Ein Helwan, \\ 11795, Cairo, Egypt \\ ${ }^{c}$ National Nutrition Institute, 16 Kasr Al Aini st., Cairo, Egypt
}

Received August 03, 2016; accepted September 09, 2016

\begin{abstract}
Febuxostat FEB was determined by differential pulse "DP" adsorptive stripping voltammetry and hanging mercury drop electrode. In $0.04 \mathrm{~mol} \mathrm{~L}^{-1}$ Britton-Robinson buffer solution, $\mathrm{pH} 10$, an irreversible electrochemical reaction took place at about -350 $\mathrm{mV}$, and the peak current was linearly varied over the concentration range of 12.5-200 $\mathrm{ng} \mathrm{mL}^{-1} \mathrm{FEB}$, with correlation coefficients of 0.9995 , after $60 \mathrm{~s}$ accumulation time, stirring at a speed of $600 \mathrm{rpm}$, rest for $10 \mathrm{~s}$, then cathodic stripping sweep from -100 to $600 \mathrm{mV}$, with a scan rate of $60 \mathrm{mV} / \mathrm{s}$. The limits of detection and quantization were $6.93,23.09 \mathrm{ng} \mathrm{mL}^{-1}$. The method was applicable for determining FEB in pharmaceutical tablets and in spiked plasma. The results of the proposed method were compared with that obtained by the UV-spectrophotometric technique.
\end{abstract}

Keywords: Febuxostat, differential pulse voltammetry, HMDE, pharmaceutical and plasma samples.

\section{Introduction}

Febuxostat (FEB), [2-[3-cyano4-(2-methylpropoxy) phenyl]-4-methylthiazole-5carboxylic acid] with the structural formula given in Fig. 1, is a xanthine oxidase inhibitor used as anti-gout drug [1].

FEB is a non-hygroscopic, white crystalline powder that is soluble in dimethylformamide and dimethylsulfoxide; slightly soluble in acetonitrile and methanol; sparingly soluble in ethanol; and practically insoluble in water. Several FEB determination methods have been reported. These included UV spectrophotometric methods [2-8], RP-HPLC-UV[9-15], RP-HPLC-MS/MS [1618] and UPLC-tandem mass [19-21].

\footnotetext{
* Corresponding author. E-mail address: ihihabib@yahoo.com
} 
In our knowledge, no work was found in the literature for the voltammetric determination of FEB, which was characterized in a highly sensitive way, down to $\mathrm{ng} \mathrm{mL}^{-1}$, as described below.

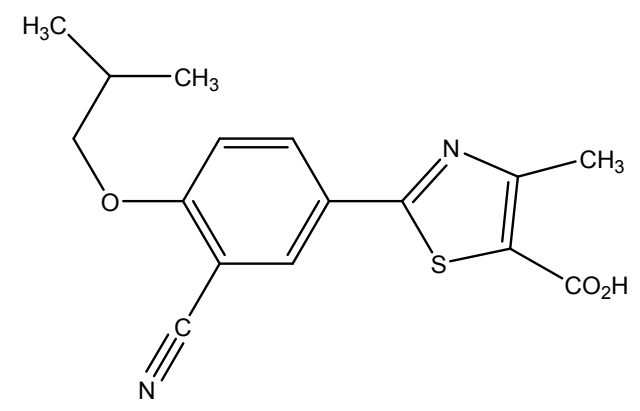

Figure 1. Structure of Febuxostat.

\section{Experimental}

Apparatus

A Metrohm voltammeter model 693 VA processor and 694 VA stand (Swiss), equipped with a $\mathrm{Ag} / \mathrm{AgCl}$ reference electrode stored in a $3.0 \mathrm{M} \mathrm{KCl}$ solution, and a platinum counter electrode, as auxiliary electrode, were employed. The hanging mercury drop electrode HMDE with a drop size of $0.30 \mathrm{~mm}^{2}$ was used as working electrode.

A spectrophotometer JASCO V-570 model was used.

A Metrohm $\mathrm{pH}$-meter model 691 with a combined electrode (glass-Ag/AgCl electrode) was used for $\mathrm{pH}$ measurements (Swiss).

\section{Materials and reagents}

All chemicals used were of analytical grade. Febuxostat, B.N EL-03/L017/15004 $(98.3 \%)$ was dedicated by Eva Pharma, Egypt. Donifoxate tablets (Eva Pharma, Egypt) were purchased from the local market in two dosage strengths, 40 and 80 mg per tablet.

Universal Britton-Robinson buffer solutions of 0.04 mol L ${ }^{-1}$ boric acid; $0.04 \mathrm{~mol}$ $\mathrm{L}^{-1}$ orthophosphoric acid, and $0.04 \mathrm{~mol} \mathrm{~L}^{-1}$ acetic acid with $\mathrm{pH}$ values $7.0-12.0$ were prepared by adjusting with suitable aliquots of $0.05 \mathrm{M}$ sodium hydroxide. Double distilled water was used throughout all experiments.

\section{Standard solutions}

A stock solution of standard FEB was first prepared by dissolving $25 \mathrm{mg}$ FEB in $5 \mathrm{~mL}$ of $0.05 \mathrm{~mol} \mathrm{~L}^{-1}$ sodium hydroxide solution, then completed to $100 \mathrm{~mL}$ with distilled water and stored in a dark and cold place. Further dilution was achieved by transferring $1 \mathrm{~mL}$ of the stock solution to a $50 \mathrm{~mL}$ measuring flask, and completing to the mark with a $2.5 \mathrm{~mol} \mathrm{~L}^{-1} \mathrm{NaOH}$ solution.

\section{Procedure}

Aliquots of a FEB solution corresponding to a concentration range of 125 - 2000 ng were sequentially added to a $10 \mathrm{~mL}$ BR buffer solution, $\mathrm{pH} 10$, and de-aerated by purging nitrogen gas for $3 \mathrm{~min}$, then pre-concentrated for $60 \mathrm{~s}$ at $-100 \mathrm{mV}$, 
with stirring at $600 \mathrm{rpm}$. After resting for $10 \mathrm{~s}$, differential pulse DP or square wave pulse SQW was scanned from -100 to $-600 \mathrm{mV}$ with a scan rate of $60 \mathrm{mV}$ $\mathrm{s}^{-1}$, pulse amplitude of $50 \mathrm{mV}$, pulse duration of $40 \mathrm{~ms}$, measurement time of 20 $\mathrm{ms}$, and frequency of $30 \mathrm{~Hz}$. The experiment was triplicate, and the average of corresponding peak current was taken. The concentration and current were plotted to calculate slope, intercept and correlation coefficient.

\section{Validation of the analytical procedure}

For the validation of studied methods, the regression parameters, precision, and accuracy were checked by essaying samples with different concentrations of FEB on the same day and different days (between days), over a period of three days, using slope and intercept, as mentioned before.

\section{Tablet essay procedure}

Contents of five coated-tablets were weighted, and then thoroughly grounded to a fine powder. A sufficient amount of the powder equivalent to one tablet was accurately weighted, dissolved in $5 \mathrm{~mL}$ of a $0.05 \mathrm{~mol} \mathrm{~L}^{-1} \mathrm{NaOH}$ solution, with a magnetic stirrer for 15 minutes, and then diluted with a sufficient amount of double distilled water, to obtain a final concentration of $400 \mu \mathrm{g} \mathrm{mL}{ }^{-1}$ FEB. Further dilution was achieved by transferring $1 \mathrm{~mL}$ of the previous solution to a $50 \mathrm{~mL}$ measuring flask, and completing to the mark with a $2.5 \mathrm{~mol} \mathrm{~L}^{-1} \mathrm{NaOH}$ solution. The aliquot of $50 \mu \mathrm{L}$ of the final solution was transferred to a voltammetric vessel containing a $10 \mathrm{~mL}$ BR buffer solution, $\mathrm{pH} 10$, to give a

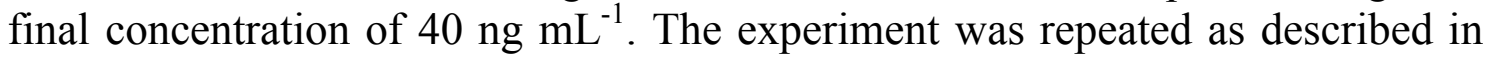
the above voltammetric procedure.

\section{Analysis of human plasma samples}

A procedure to extract FEB from spiked human plasma was achieved as described by Monita et al. [14], which can be detailed as it follows:

Drug-free plasma samples were obtained from healthy people, and stored frozen in the dark until the essay. $1 \mathrm{~mL}$ of the plasma sample spiked with $2.5 \mu \mathrm{g} \mathrm{mL}{ }^{-1}$ methanolic solution of FEB was placed in a glass tube of $15 \mathrm{~mL}$ capacity, and 5 $\mathrm{mL}$ diethylether was added. The contents of the tube were mixed by a vortex mixer for $2 \mathrm{~min}$, shaken by a shaker at 100 strokes per min for $45 \mathrm{~min}$, and then centrifuged for $15 \mathrm{~min}$ at $3000 \mathrm{rpm}$ at $4{ }^{\circ} \mathrm{C}$, to precipitate plasma protein residues. The organic layer was pipetted out into a $25 \mathrm{~mL}$ beaker, evaporated to dryness in air at room temperature, and re-dissolved in $5 \mathrm{~mL} 2.5 \mathrm{~mol} \mathrm{~L}^{-1} \mathrm{NaOH}$. The solution was then filtered through a PTFE $0.45 \mu \mathrm{m}$ filter. $1 \mathrm{~mL}$ of the filtrate was transferred into a $10 \mathrm{~mL}$ measuring flask, and completed to the mark with a BR buffer solution, $\mathrm{pH}$ 10. The voltammetric measurement was repeated as described above.

\section{Results and discussion}

Different chemical and electrochemical parameters were thoroughly investigated to study the voltammetric behavior of FEB. 


\section{Effect of $p H$}

The effect of $\mathrm{pH}$ on peak potential and current was studied in Britton-Robinson "BR" buffer solutions in the range of $\mathrm{pH} \mathrm{8-11.} \mathrm{In} \mathrm{the} \mathrm{cathodic} \mathrm{direction} \mathrm{from} \mathrm{-}$ 100 to $-600 \mathrm{mV}$, the peak was shifted towards more-negative potential values by increasing the $\mathrm{pH}$ up to 11 , and the corresponding peak current was also increased; but reached a maximum value on using a BR solution of $\mathrm{pH} 10$, as shown in Fig. 2. The cathodic peak was also shown on using $0.3 \mathrm{~mol} \mathrm{~L}^{-1} \mathrm{KCl}$, but it gave less peak symmetry with a lower peak height, and so, a BR buffer solution of $\mathrm{pH} 10$ was selected in the next studies. No peaks were observed in the anodic direction in the same electrolyte media, suggesting that the electrochemical process is irreversible. To evaluate the number of protons relative to the number of electrons, the following equation is applied:

$$
E_{p}=E^{=}-\frac{R T}{n F} \ln \frac{[0 x]}{[R \sigma d]} \pm \frac{2.303 \partial R T}{n F} p H
$$

where, $\mathrm{E}^{\circ}$ is the standard peak potential in Volts, $\partial$ is the number of protons, $n$ is the number of electrons transferred in the mechanism, $R$ is the ideal gas constant $\left(8.314 \mathrm{~J} \mathrm{~K}^{-1} \mathrm{~mol}^{-1}\right), T$ is the absolute temperature $(298 \mathrm{~K}), F$ is Faraday's constant $\left(96485\right.$ coulomb $\left.\mathrm{mol}^{-1}\right),[\mathrm{Ox}]$ and [Red] are the equilibrium concentrations of reduced and oxidized species, respectively. The plot of the peak potential $\mathrm{E}_{\mathrm{p}}$ versus $\mathrm{pH}$ showed one straight line between 8.0 and 11.0, with slope equal to 0.058 , which is close to the Nernst theoretical value of $0.059 \mathrm{~V} \mathrm{pH}$ [22]; the ratio of protons to electrons $\partial / n$ that participated in the mechanism was calculated as 0.986 , indicating a participation of an equal number of protons and electrons in the FEB reduction [23].

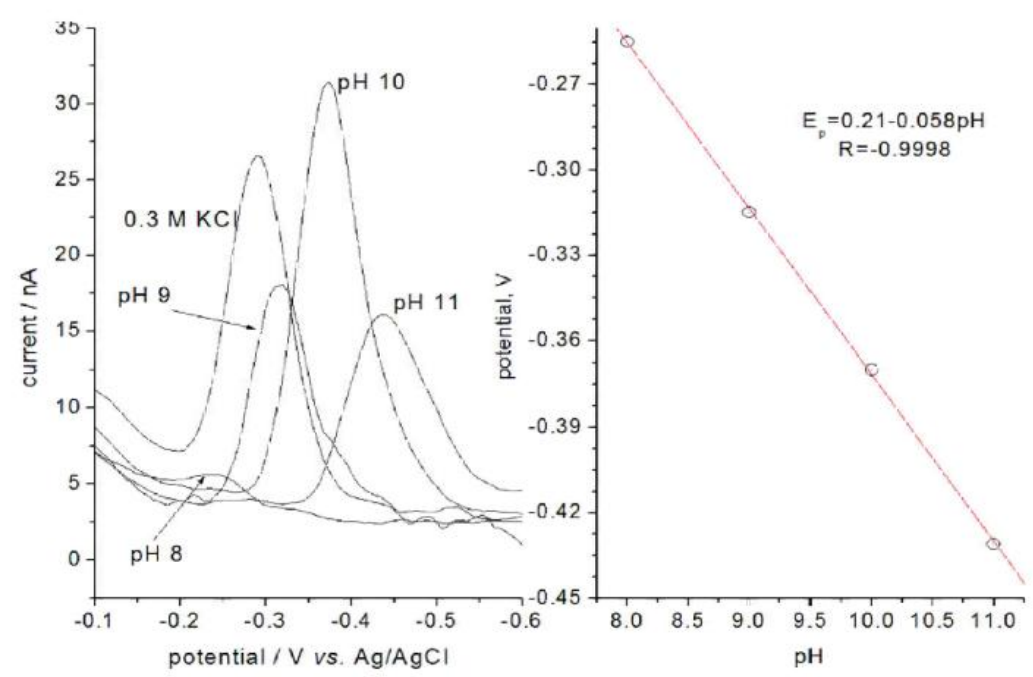

Figure 2. Variation of $\mathrm{pH}$ with FEB's potential reduction.

\section{Effect of scan rate}

The irreversibility of FEB's electrochemical reaction was also confirmed by variations of scan rate with potential, as given in Fig. 3, where the peak potential was shifted to a more negative potential, after increasing the scan rate. 
For this kind of irreversible mechanism, electron transfer coefficient $\alpha$, and heterogeneous catalytic reaction rate constant $\mathrm{K}_{\mathrm{s}}$ were determined using Laviron's equation [24, 25] as it follows:

$$
E_{p}=E^{*}+\frac{2.3 R T}{\alpha n F} \log \frac{R T K_{s}}{\alpha n F}+\frac{2.3 R T}{\alpha n F} \log \tau
$$

where $E_{p}$ is the peak potential in volts and $v$ is the scan rate $\left(\mathrm{Vs}^{-1}\right) . K_{s}$ and $\alpha$ n values can be concluded from the slope and intercept of the linear plot of $E_{p}$ with respect to $\log v$ (Fig. 3, right).

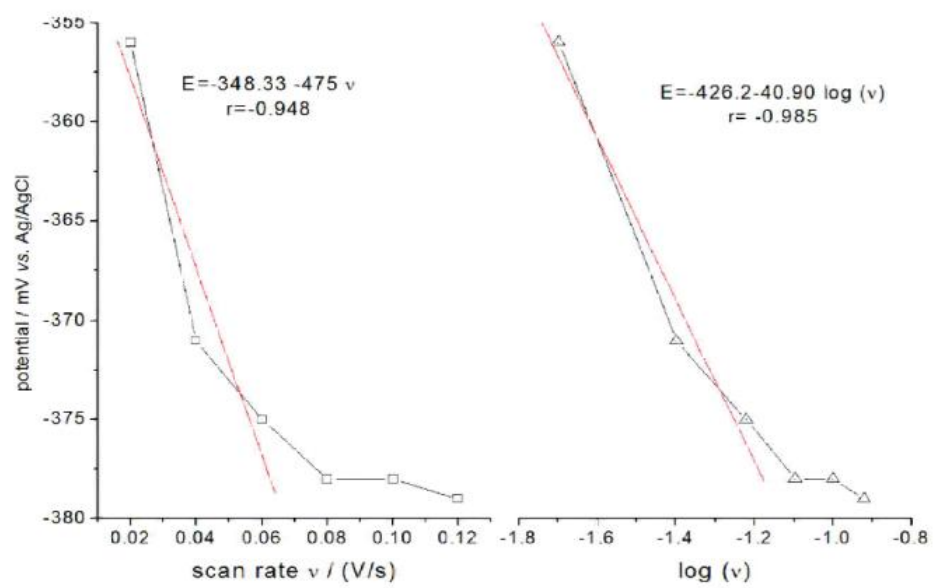

Figure 3. Variation of scan rate with FEB's potential reduction in a BR buffer solution $\mathrm{pH} 10$.

The $E^{\circ}$ value can be deduced from the intercept of Ep versus $v$ on the ordinate by extrapolating the line to $\mathrm{v}=0$ (Fig. 3, left). Knowing $E^{\circ}$, which equals to -348 $\mathrm{mV}$, and from the graphical representations of $E_{p}$ versus $\log v$ for FEB, the values of $\alpha n=1.446$ and $k_{s}=2.05 \times 10^{-18} \mathrm{~s}^{-1}$ were obtained from the slope and intercept, respectively.

Since for a totally irreversible electron transfer, $\alpha$ is the range from 0.30 to 0.70 , the number of electrons transfer $n$ for the reduction step is most probably 4 , which indicated that four electrons were involved in FEB's reduction on HMDE. Thus, at the electrode interface, 4 protons and 4 electrons were probably consumed to convert nitrile $-\mathrm{C} \equiv \mathrm{N}$ into amino group $-\mathrm{CH}_{2}-\mathrm{NH}_{2}$, resembling to that proposed by [26].

The variation of the logarithm of the peak current versus the logarithm of the scan rate in the range of $20-120 \mathrm{mV} \mathrm{s}^{-1}$ showed that the process has effected adsorption for HMDE electrode, the relation was linear over the range 20-60 mV $\mathrm{s}^{-1}$, and its slope was equal to 0.7 , which is close to the theoretical value of 1.0 for some adsorption controlled effects [27] (Fig. 4).

\section{Effect of accumulation time}

The effect of accumulation time on the adsorptive cathodic stripping peak currents was studied on the concentrations of 25.5, 153, $204 \mathrm{ng} \mathrm{mL}^{-1}$. As shown in Fig. 5, the current was linearly increased by increasing the accumulation time $\left(\mathrm{t}_{\mathrm{a}}\right)$, and began to deviate beyond $60 \mathrm{~s}$, due to the formation of a multilayer of the 
cited drug on the surface of the mercury electrode. The accumulation time of $60 \mathrm{~s}$ was selected.

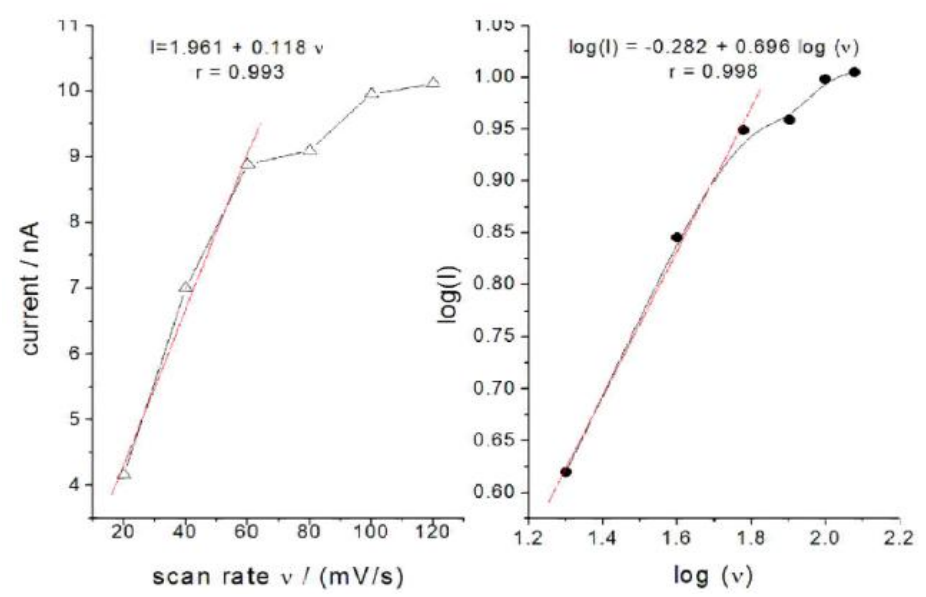

Figure 4. Variation of FEB's peak current with scan rate in a $0.04 \mathrm{M} \mathrm{BR}$ buffer solution, $\mathrm{pH} 10$.

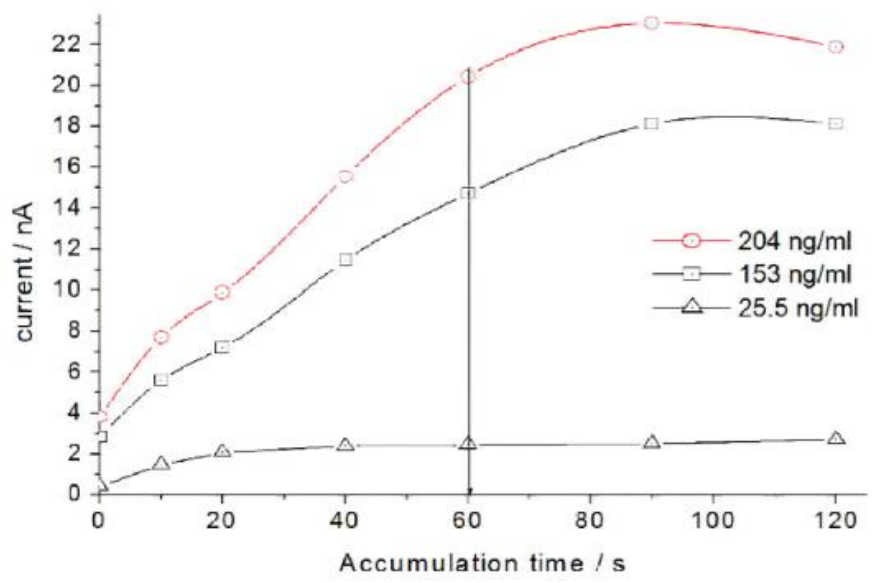

Figure 5. Variation of peak current with FEB's accumulation time at an accumulation potential of $-100 \mathrm{mV}$, and a $0.04 \mathrm{M}$ BR buffer solution, $\mathrm{pH} 10$.

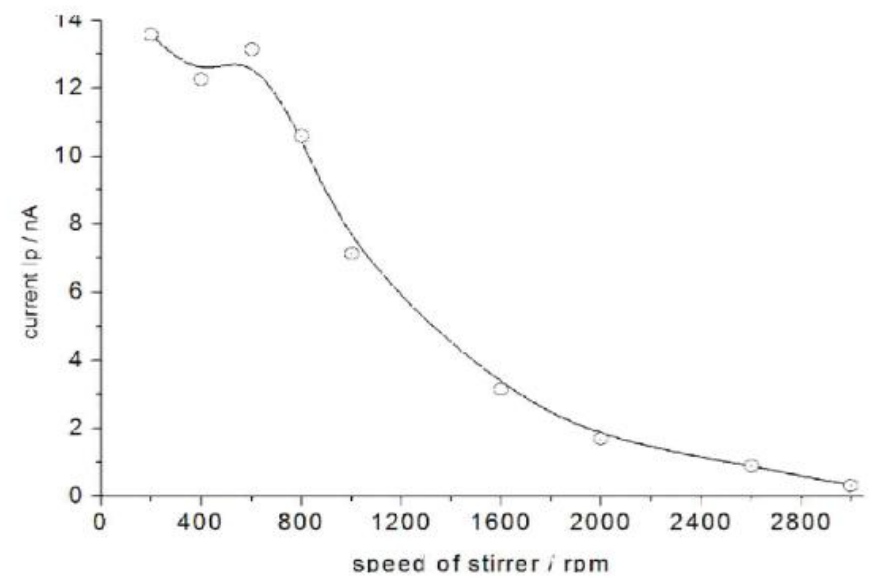

Figure 6. Variation of peak current with speed of stirrer at potential $-100 \mathrm{mV}$, scan rate of $60 \mathrm{mV} \mathrm{s}^{-1}$ and accumulation time of $60 \mathrm{~s}$ in a $0.04 \mathrm{M}$ BR buffer solution, $\mathrm{pH} 10$. 


\section{Stirring effect}

The stirring effect on the adsorptive cathodic stripping peak currents was studied on concentration of $153 \mathrm{ng} \mathrm{mL} \mathrm{m}^{-1}$; it was found that the current was increased by increasing the stirring speed till $600 \mathrm{rpm}$, and then dropped down gradually with further speed up to $3000 \mathrm{rpm}$, as observed in Fig. 6. The stirring speed of 600 rpm was selected.

\section{Effect of-pulsation mode}

Based on the above selected parameters of a $0.04 \mathrm{M}$ BR buffer solution, $\mathrm{pH} 10$, scan rate of $60 \mathrm{mV} \mathrm{s}^{-1}$, accumulation time of $60 \mathrm{~s}$, stirring speed of $600 \mathrm{rpm}$, Figs. 7 and 8 demonstrated the effect of two types of pulsation to sweep, viz. square wave SQW and differential pulse DP. It is clear that the peak heights of DP current are lower than those of SQW, however, DP mode was selected because the cathodic peaks were practically more symmetric and reproducible than by SQW mode. The results showed good linearity over the concentration range from 12.5 to $204 \mathrm{ng} \mathrm{mL}{ }^{-1}$, with more favorable regression parameters given by DP than those by SQW, as it is showed in Table 1.

Table 1. Regression parameter for determination of febuxostat using DP and SQW.

\begin{tabular}{|l|l|c|}
\hline Parameter & \multicolumn{1}{|c|}{ DP } & \multicolumn{1}{c|}{ SQW } \\
\hline Range $\left(\mathrm{ng} \mathrm{mL} \mathrm{mL}^{-1}\right)$ & \multicolumn{2}{|c|}{$12.75-204$} \\
\hline Slope & 0.0758 & 0.116 \\
\hline Intercept & -0.353 & -1.528 \\
\hline Correlation coefficient $\left(\mathrm{R}^{2}\right)$ & 0.9995 & 0.9969 \\
\hline $\mathrm{E}_{\mathrm{y} / \mathrm{x}}$ & 0.175 & 0.657 \\
\hline LOD $(\mathrm{ng} / \mathrm{mL})$ & 6.93 & 16.99 \\
\hline LOQ $(\mathrm{ng} / \mathrm{mL})$ & 23.09 & 56.64 \\
\hline
\end{tabular}

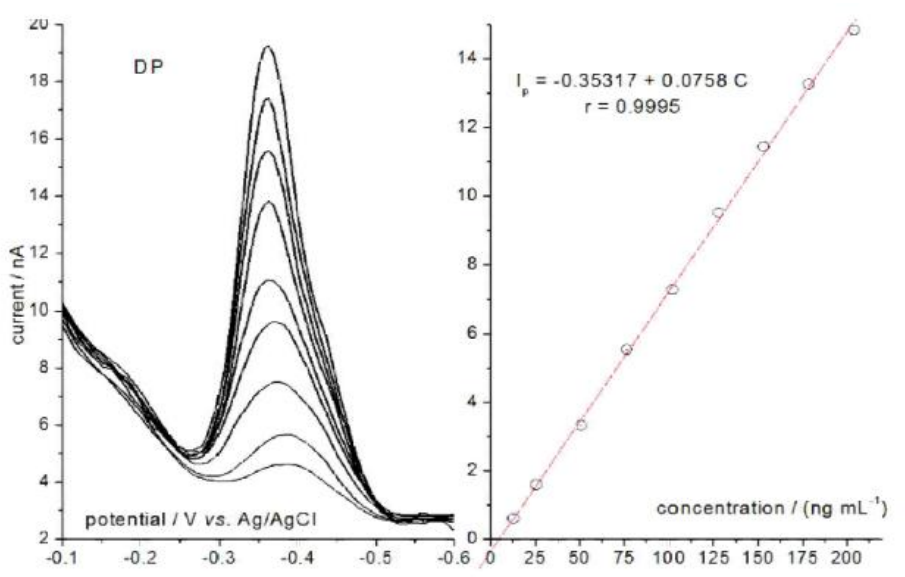

Figure 7. Calibration curve of peak current versus concentration of FEB using differential pulse sweep.

\section{Validation of the analytical procedure}

For the validation of the studied method, the regression parameters, precision, and accuracy were checked, as given in Table 2, by essaying triplicate samples on the same day and different days (between days) over a period of three days, for different concentrations of FEB, and using DP mode. It is clear that there is no significance difference between intra and inter days in terms of accuracy and 
precision, and the 95\% confidence interval revealed that the source of error is likely random on determining FEB.

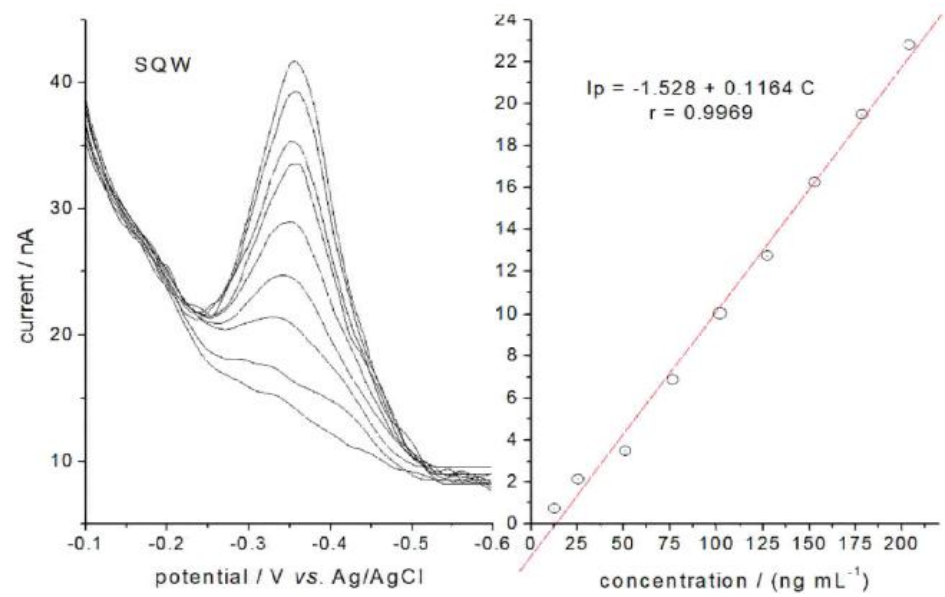

Figure 8. Calibration curve of peak current versus concentration of FEB using square wave sweep.

Table 2. Accuracy and precision of the proposed method.

\begin{tabular}{|c|c|c|c|c|c|c|c|c|}
\hline \multirow{3}{*}{$\begin{array}{c}\text { Taken } \\
\text { ng mL } \mathbf{~}^{-1}\end{array}$} & \multicolumn{6}{|c|}{ Intra-days } & \multicolumn{2}{|l|}{ Inter-days } \\
\hline & $\begin{array}{c}\text { Accuracy } \\
\%\end{array}$ & $\begin{array}{l}\text { Precision } \\
\text { (RSD) }\end{array}$ & $\begin{array}{c}\text { Accuracy } \\
\%\end{array}$ & $\begin{array}{l}\text { Precision } \\
\text { (RSD) }\end{array}$ & $\begin{array}{c}\text { Accuracy } \\
\%\end{array}$ & $\begin{array}{l}\text { Precision } \\
\text { (RSD) }\end{array}$ & $\begin{array}{c}\text { Accuracy } \\
\%\end{array}$ & $\begin{array}{l}\text { Precision } \\
\text { (RSD) }\end{array}$ \\
\hline & \multicolumn{2}{|c|}{$\mathbf{1}^{\text {st }}$ day } & \multicolumn{2}{|c|}{$2^{\text {nd }}$ day } & \multicolumn{2}{|c|}{$3^{\text {rd }}$ day } & \multicolumn{2}{|c|}{3 days } \\
\hline 25.37 & 104.70 & 5.14 & 103.57 & 0.91 & 101.35 & 2.13 & 103.21 & 1.65 \\
\hline 50.50 & 96.83 & 0.98 & 97.83 & 2.25 & 98.64 & 0.65 & 97.77 & 0.93 \\
\hline 75.37 & 103.59 & 1.35 & 96.32 & 1.27 & 99.31 & 0.24 & 99.74 & 3.66 \\
\hline 100.00 & 94.66 & 1.33 & 99.98 & 2.18 & 100.78 & 0.33 & 98.47 & 3.38 \\
\hline 124.39 & 100.60 & 1.75 & 100.62 & 3.35 & 102.57 & 0.81 & 101.27 & 1.12 \\
\hline 148.54 & 101.20 & 1.08 & 102.72 & 0.57 & 100.89 & 0.29 & 101.61 & 0.96 \\
\hline 172.46 & 101.89 & 0.88 & 101.00 & 0.77 & 100.56 & 0.34 & 101.15 & 0.67 \\
\hline 196.15 & 98.59 & 1.33 & 98.17 & 0.88 & 98.97 & 0.71 & 98.58 & 0.40 \\
\hline 219.62 & 95.77 & 0.78 & 95.04 & 0.57 & 98.50 & 0.45 & 96.43 & 1.89 \\
\hline $\begin{array}{l}\text { Accuracy } \\
\text { (Bias), RE }\end{array}$ & -0.24 & & -0.53 & & 0.18 & & -0.20 & \\
\hline $\begin{array}{l}\text { Precision, } \\
\text { RSD }\end{array}$ & 3.51 & & 2.86 & & 1.39 & & 2.17 & \\
\hline $\begin{array}{l}\text { Confidence } \\
\text { interval at } \\
\alpha=0.05, n=9\end{array}$ & 2.29 & & 1.87 & & 0.91 & & 1.42 & \\
\hline
\end{tabular}

\section{Application to dosage form}

The proposed method was applied for the determination of FEB in tablets of 40 and $80 \mathrm{mg}$ FEB per tablet, and the results show 101.27-100.13\% recovery, respectively (Table 3), which indicates that the method is selective for the essay of FEB without interference from the excipients used in these tablets. This is in agreement with that obtained by UV-spectrophotometric method [5] within the accuracy and precision limits. 
Table 3. Application of the proposed method for determining FEB in different pharmaceutical products, and comparison with spectrophotometric method as reference method.

\begin{tabular}{|l|c|c|}
\hline & \multicolumn{2}{|c|}{ Found \pm RSD, \% } \\
\hline Tablet & Proposed method* $^{*}$ & Reference method [5] \\
\hline Donifoxate $40 \mathrm{mg}$ & $101.27 \pm 0.8$ & $100.7 \pm 0.5$ \\
\hline Donifoxate $80 \mathrm{mg}$ & $100.13 \pm 1.2$ & $99.4 \pm 0.6$ \\
\hline$t$-test, $t_{\text {table }}=2.57^{* *}$ & \multicolumn{2}{|c|}{0.612} \\
\hline$F$-test, $F_{\text {table }}=5.05^{* *} 3.306$ \\
$*$ Mean of three determinations; ${ }^{* *}$ significance level at 5\% and degrees of freedom at 5
\end{tabular}

\section{Application to plasma form}

The plasma protein binding of FEB is known to be approximately $99.2 \%$, (primarily to albumin) [21], and in order to evaluate the applicability of the proposed method to extract and determine the bound FEB, the recovery was found to be in the range $70-73 \%$, which is in accordance with that obtained by Monita et al. [14]. It is worth mentioning that FEB was not detectable on spiking the plasma with an aqueous solution of FEB in $\mathrm{NaOH}$. This may be attributed to the formation of an ionic compound which was not extractable by diethylether. This could be solved by spiking with a methanolic solution of FEB.

\section{Conclusions}

The reduction of FEB is $\mathrm{pH}$ dependent, and it is an irreversible process in a 0.04 M Britton-Robinson buffer solution, involving 4 electrons transfer at HMDE interface, to convert nitrile into amine group. The differential pulse voltammetric method was applied to direct quantification of FEB in tablets and human plasma.

\section{Acknowledgements}

Thanks are due to Volkswagen Stiftung, Kastanienallee 35, 30519 Hannover, Germany, for the financial support of purchasing the Metrohm model $693 \mathrm{VA}$ processor and 694 VA stand.

\section{References}

1. Sean CS. Martindale. 2nd edition. UK: Pharmaceutical Press; 2009. p 558.

2. Bagga P. A simple UV spectroscopic method for the determination of Febuxostat in bulk and pharmaceutical formulations. IJPSR. 2011, 2:26552659.

3. Heth M, Joshi S, Patel M. Development and application of difference spectrophotometric method for the determination of Febuxostat in tablets. IJPSR 2012;3:1621-1624.

4. Lakade SH, Bhalekar MR: Development and validation of new spectroscopic method for determination of Febuxostat in tablet dosage forms. J Pharm Res. 2011;4:122. 
5. Muvvala SS, Pavuluri MM, Ratnakaram VN. Simple and validated UV spectroscopic method for the estimation of Febuxostat in bulk and pharmaceutical dosage forms. Oriental J Chem. 2013;235-240.

6. Rajyalakshmi C, Benjamin T, Babu CR. Development and validation of zero and first order derivative UV-spectrophotometric method for determination of Febuxostat in bulk and in formulation. Res $\mathrm{J}$ Pharm Technol. 2013;6:208-212.

7. Raviteja N, Siva NS, Gayathri S, et al. Development and validation of UV spectroscopic method of Febuxostat in bulk and tablet formulations. IJCPS. 2013;1:337-341.

8. Sowjanya G, Srinivas L, Rajasri A. New validated UV spectrophotometric methods for the determination of Febuxostat in bulk and formulation. CIBTech J Pharma Sci. 2014;3:7-13.

9. Rao S, Reddy B, Nallagatla VB. A stability indicating RP-HPLC method development for determination of Febuxostat in tablet dosage form Caribbean. J Sci Technol. 2013;228-237.

10. Mathrusri AM, Sai P, Kumar B, et al. Development and validation of a stability-indicating RP-HPLC method for the determination of Febuxostat (a Xanthine Oxidase Inhibitor). J Chromatogr Sci. 2012;1-8.

11. Mukthinuthalapati MA, Bandaru SP, Bukkapatnam V, et al. Development and validation of a stability-indicating RP-HPLC method for the determination of febuxostat (a xanthine oxidase inhibitor). J Chromatogr Sci. 2013;51:931-938.

12. Nageswara RK, Ganapathy S, Lakshmana RA. Development and validation of RP-HPLC method for estimation of Febuxostat in bulk and tablet dosage form. IJPSR. 2010, 2:2231-2241.

13. Sameer HL, Bhalekar M, Minal TH. Development and validation of RPHPLC method for the determination of Febuxostat in bulk and formulations. IJCPS. 2012;4:1475-1491.

14. Monita G, Pankaj S, Ravindra S, et al. Method development and validation for determination of Febuxostat from spiked human plasma using RPHPLC with UV detection. Chromatogr Res Int. 2014;1.

15. Cong Z, Shao-Jie W, Rong-Li M, et al. Determination of content of febuxostat and its related substances by HPLC. J Shenyang Pharmac Univ. 2010;27:648-651.

16. Xie H, Wang Z, Deng K, et al. An HPLC-MS/MS method for simultaneous determination of the active metabolites of febuxostat $(67 \mathrm{M}-1,67 \mathrm{M}-2$ and 67M-4) in human plasma. J Chromatogr B Analyt Technol Biomed Life Sci. 2014;970:24-30.

17. Shi Z, Liu J, Hu XJ, et al. Development of a simple LC-MS/MS method for the determination of febuxostat in human plasma and its application to a bioequivalence study. Pharmazie. 2013;68:396-400.

18. Babu Rao C, Kanchanamala K, Nagiat TH, et al. Springer Plus. 2013;2:194.

19. Wu Y, Mao Z, Liu Y, et al. Simultaneous determination of febuxostat and its three active metabolites in human plasma by liquid chromatography- 
tandem mass spectrometry and its application to a pharmacokinetic study in Chinese healthy volunteers. J Pharm Biomed Anal. 2015;114:216-221.

20. Zhang T, Sun Y, Zhang P, et al. Ultra-performance liquid chromatographytandem mass spectrometry method for the determination of febuxostat in dog plasma and its application to a pharmacokinetic study. Biomed Chromatogr. 2013;27:137-141.

21. Lukram O, Parmar S, Hande A. Determination of febuxostat in human plasma using ultra-performance liquid chromatography tandem mass spectrometry. Drug Test Anal. 2013;5:492-499.

22. Bard AJ, Faulkner LR. Electrochemical methods, fundamentals and applications. New York: Wiley; 2001.

23. Tas-demir H, Cakırer O, Erk N. Square-wave cathodic adsorptive stripping voltammetry of risperidone. Collect Czech Chem Comm. 2011;76:159.

24. Laviron E. Adsorption, autoinhibition and autocatalysis in polarography and in linear potential sweep voltammetry. J Electroanal Chem. 1974; 52:355-365.

25. Laviron E. General expression of the linear potential sweep voltammogram in the case of diffusionless electrochemical systems. J Electroanal Chem. 1979;101:19-28.

26. Lai-Hao W, Hsien-Ju T. Electroanalytical kinetic and diffusion studies for the reduction of 4-Cyano-3-substituted Sydnones. J Chin Chem Soc. 2003, 50:23-30.

27. Laviron E, Roullier L, Degrand C. A multilayer model for the study of space distributed redox modified electrodes. 2. Theory and application of linear potential sweep voltammetry for a simple reaction. J Electroanal Chem. 1980;112:11-23. 